\title{
Do I need to see a psychologist?
}

\author{
WC WATSON, MD, PHD, FRCP(LOND), FRCPC
}

\section{P} YCHOLOGY IS THE SCIENCE OR study of the mind, behaviour and attitudes, and a psychologist is someone engaged in that field. Therefore, when you ask the question, "Do I need to see a psychologist?", the assumption is that you are concerned whether your mind, behaviour, feelings and attitudes have any connection with your condition whether they affect it or it affects them. But more than that you are wondering, indeed hoping, that you will learn or discover something that will be helpful or healing. Some of the feelings and attitudes that individuals with inflammatory bowel disease (IBD) experience are listed in Table 1.

It is helpful and often a relief to know that virtually everyone with IBD gets some or all of these feelings. You are not alone. Not only that, but people with many other conditions get these feelings too-patients with cancer or multiple sclerosis, or cystic fibrosis or disfiguring skin diseases, or rheumatoid arthritis, or paraplegics.

The most common questions asked by people with physically and socially disabling diseases are "Am I responsible for it?" or "Is it something I have done?". In some conditions the answer is 'yes',

\author{
TABLE 1 \\ Feelings and attitudes that individuals with inflammatory bowel disease \\ experience

\begin{tabular}{ll}
\hline Feelings & Reason \\
\hline Tiredness & You are anemic or undernourished \\
Depression & You are fed up, low in spirits \\
Frustration & The disease is so unpredictable, such a nuisance \\
Anger and resentment & Why is it happening to me? \\
Anxiety & What about my future, my career, my livelihood, my \\
Rejection and alienation & Nobody wants to employ me, or get too close to me \\
Inferiority & At times I hate myself, I feel defiled \\
Guilt & Aml responsible for my disease because of my \\
& behaviour? \\
\hline
\end{tabular}

as in smoking, heavy drinking, or drug abuse, not wearing a seatbelt or overeating.

But not in connection with the cause of IBD. That needs to be stressed repeatedly. IBD is due to an organic, physical cause that has not yet been identified. It is not due to psychological mechanisms.

Psychological support may help the patient feel better. It does not significantly influence the physical aspects of the condition.

Whether individuals regard themselves as religiously inclined or not, the notion that sin causes disease is still remarkably entrenched, even among the very sophisticated. Sin is only one aspect of behaviour. In one of the healing miracles in the New Testament the disciples asked if the man was blind because he or his parents had sinned. Christ's answer was "neither". The notion of expiation for $\sin$ by disease persists. Patients with IBD must not punish themselves with this additional load of misplaced and inappropriate guilt.

But having the attitudes and feelings that are listed above because of the disease is another matter altogether.

It is difficult to feel the life and soul of the party when your hemoglobin is low, you are losing weight, losing sleep and having copious diarrhea. It is so 
frustrating not to know from one day, month or year to the next whether you will be in or out of hospital, have to cancel your holidays or turn down a job offer. When everyone else around you seems to enjoy good health and can do what they like when they like, it is easy to become angry and resentful. Of all the negative feelings that human beings have, resentment may be the worst and most destructive.

But feelings like these, understandable as they may be, do not help. They consume mental, emotional and even physical energy that can be put to better use - like helping others who may be less well than you are, by understanding and support 'wrestling misfortune to the ground'. Three such individuals are described below.

Andrew is in his 30 s. He was employed by a bank. He had a number of admissions to hospital, did not get on well with his manager, did not get on with me at times, had a chip on his shoulder, and was becoming increasingly resentful about the restrictions on career advancement. Then one day he made a remarkably courageous decision. He decided to take his fate into his own hands, resign from the bank (which at least provided some security) and set up his own business. He knows it may fail, but the boost to his morale and sense of self-esteem has been enormous. I never saw him look better than on the day he told me he had made his decision.

Brenda is in her early 20s. She has a hard life as a waitress. Her disease has virtually never been under control. She is on and off steroids, metronidazole, and has been in hospital once or twice for intravenous feeding. She gains weight and loses it again. And all of this time she has never seemed to be sorry for herself. And apart from necessary visits to hospital she never misses a day from work. In spite of her illness her employer has tremendous respect for her tenacity and dependability.

Stefan is in his 70s. He is a man of remarkably independent spirit who emigrated from eastern Europe many years ago and came within half a day of a total colectomy five years ago. He enjoys talking about his hard life, without bitterness and often with a mischevious twinkle in his eye. From time to time he is wilfully noncompliant, not taking his medicine when he should or too much of it when he should not. On these occasions he tells me he thinks he knows how to treat his disease better than I do. And he may be right.

These three individuals exemplify what the poet Dryden calls "courage in distress".

But now it is time to return to the starting question - "do you need to see a psychologist?"

What do you think yourself? What would you expect to get out of the experience?

You will not get the answer as to why you have IBD. You should get reassurance that it is not your own fault. But most of all you should receive understanding. Psychologists do not prescribe medicines. They provide insight and explanation. They lend a sympathetic and wise ear. They are counsellors in the broadest and wisest sense of the term. They cannot make the disease better, but they can help you to feel better and have a better attitude to your condition.

However, you may feel that you do not need this help. Your relationship with your primary doctor may be sufficient and insofar as he or she knows most about the physical aspects of your condition, they are best placed to correlate them with your feelings. Or you may find that your membership in and attendance at meetings of your local chapter of the Canadian Foundation for Ileitis and Colitis (CFIC) gives you as much support and understanding as you need, through the fellowship and community of the members as well as through the information and encouragement that comes from the formal presentations.

Perhaps the single most helpful thing of all is the CFIC slogan - 'The Pain is Real'. It is not in your head and you are an important member of a suffering, supportive community.

Finally, if you feel you would like to see a psychologist, discuss it with your doctor first. That is simple courtesy and good sense. Trust is important. You are in a long term relationship with your doctor. Besides, he or she should be well placed to refer you to a suitable person, someone who at best will have a special interest in the psychological effects of IBD, or who at least will have a general interest in the subject.

Having said all of this, it is nonetheless important to remember that the psychoemotional health of the IBD patient is best when the disease is under control, which implies minimal disease activity and least probability of relapse. Your role is to cooperate with your physician, particularly in the matter of taking medicines at the right time, in the right way and in the right dosage. And if you have to travel, then in the famous words of Karl Malden "Don't leave home without them".

SUPPLEMENTARY READING: The Canadian Foundation for Ileitis and Colitis pamphlet Psychological Aspects of Inflammatory Bowel Disease. To obtain a copy, please write to: The Canadian Foundation for Ileitis and Colitis, 21 St Clair Avenue East, Toronto, Ontario M4T 1L9. 


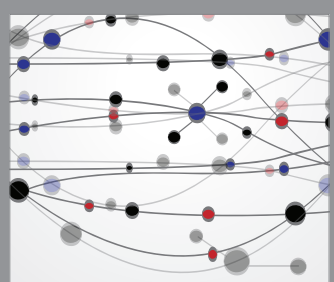

The Scientific World Journal
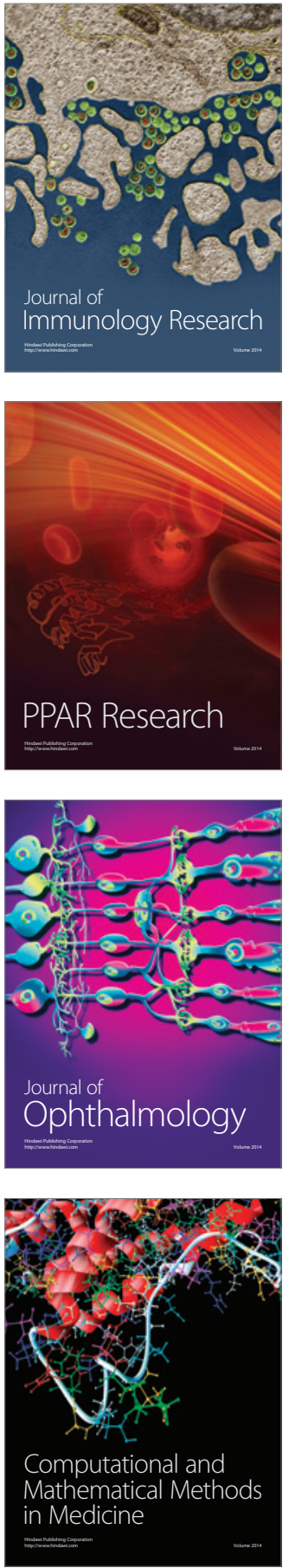

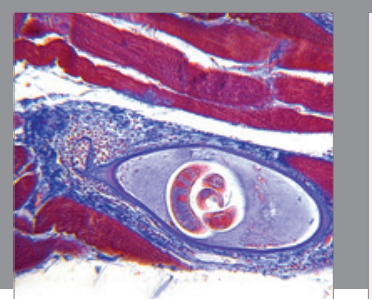

Gastroenterology Research and Practice

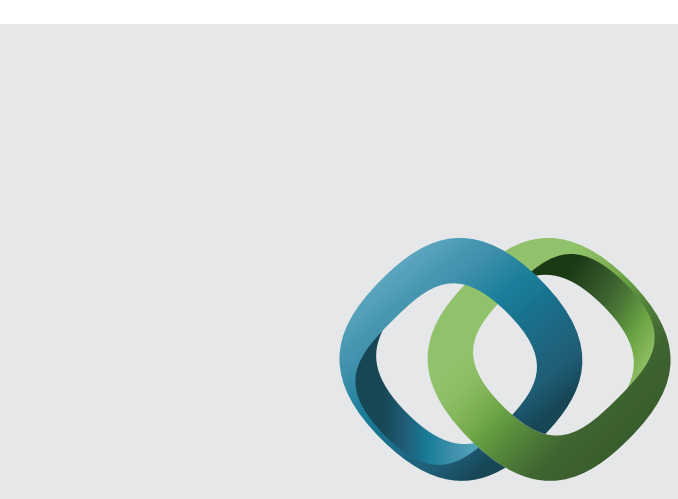

\section{Hindawi}

Submit your manuscripts at

http://www.hindawi.com
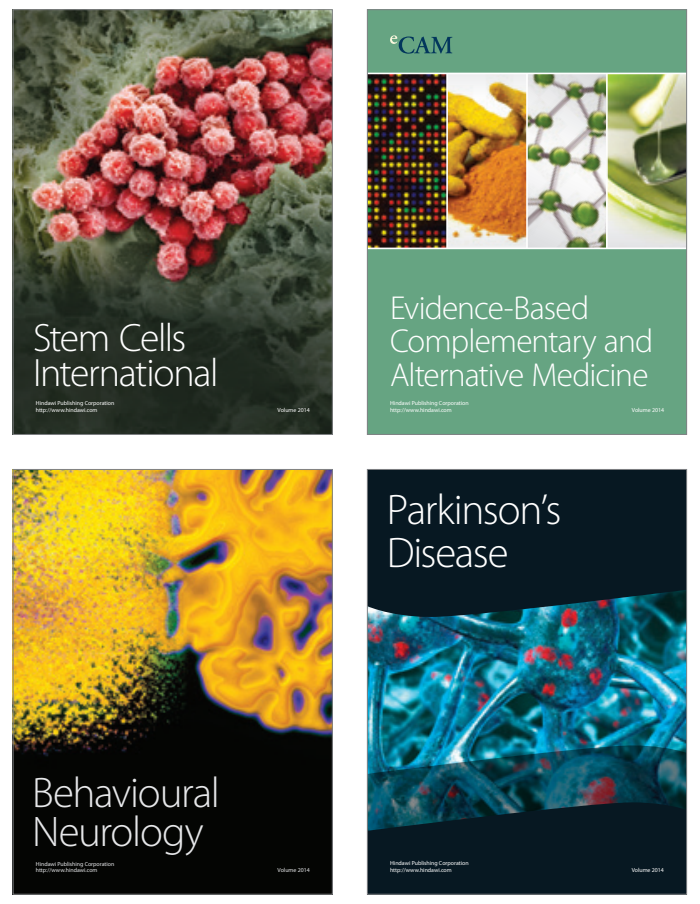
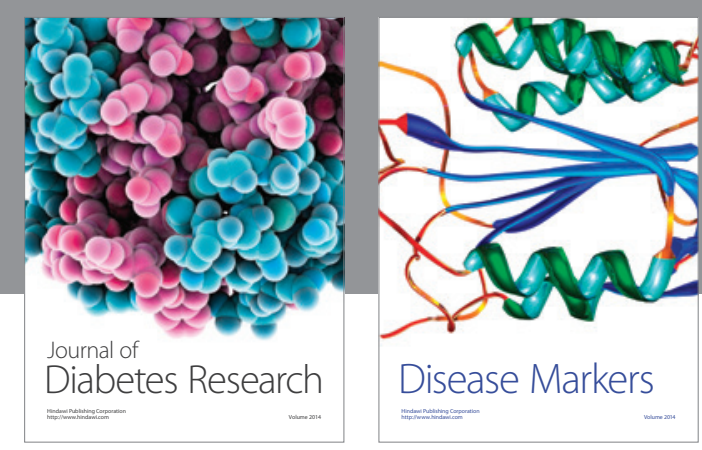

Disease Markers
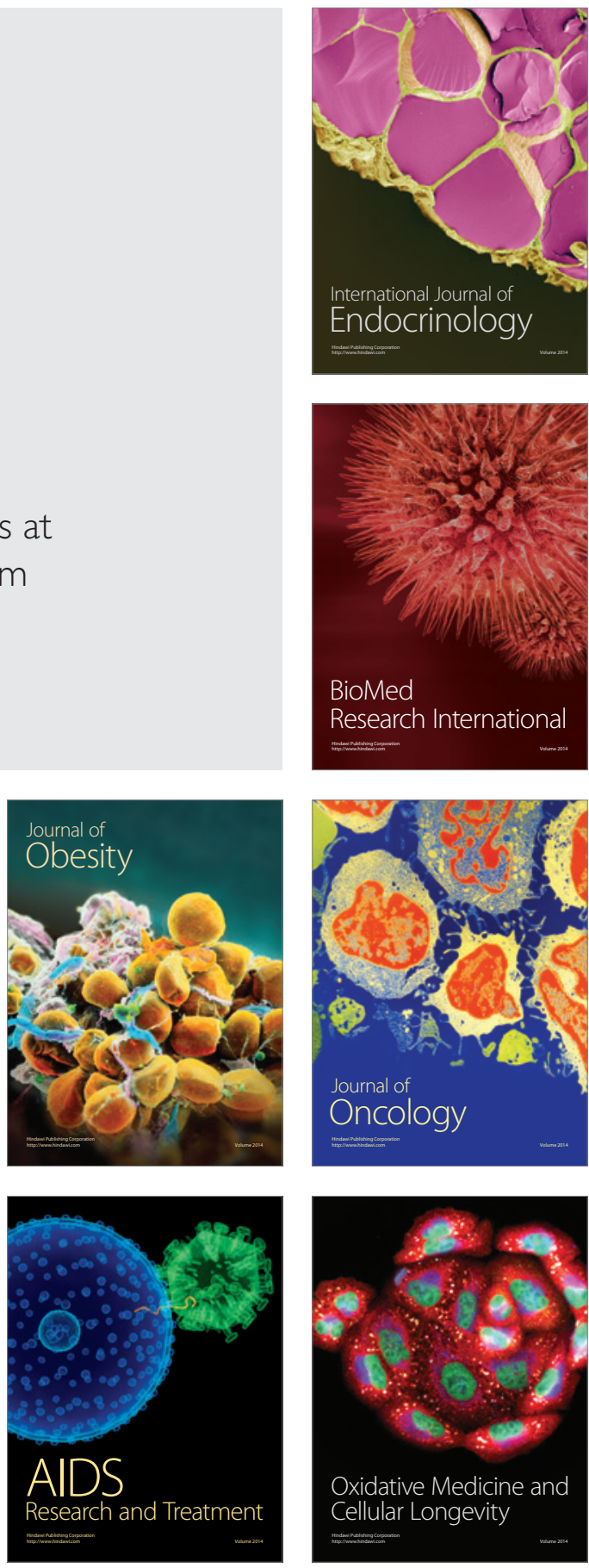